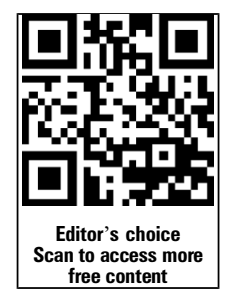

\title{
Comorbidity in severe asthma requiring systemic corticosteroid therapy: cross-sectional data from the Optimum Patient Care Research Database and the British Thoracic Difficult Asthma Registry
}

\author{
Joan Sweeney, ${ }^{1}$ Chris C Patterson, ${ }^{2}$ Andrew Menzies-Gow, ${ }^{3}$ Rob M Niven, ${ }^{4}$ \\ Adel H Mansur, ${ }^{5}$ Christine Bucknall, ${ }^{6}$ Rekha Chaudhuri, ${ }^{7}$ David Price, ${ }^{8}$ \\ Chris E Brightling, ${ }^{9}$ Liam G Heaney, ${ }^{1}$ on behalf of the British Thoracic Society Difficult \\ Asthma Network
}

\begin{abstract}
- Additional material is published online only. To view please visit the journal online (http://dx.doi.org/10.1136/ thoraxjn-2015-207630)

For numbered affiliations see end of article.
\end{abstract}

\section{Correspondence to Professor Liam G Heaney, Centre for Infection and Immunity, Queen's University of Belfast, Wellcome-Wolfson Institute for Experimental Medicine, 97 Lisburn Road, Belfast BT9 7BL, UK; jsweeney13@qub.ac.uk}

Received 3 August 2015 Revised 16 December 2015 Accepted 28 December 2015 Published Online First 27 January 2016

\section{SLinked}

- http://dx.doi.org/10.1136/ thoraxinl-2015-208242

\section{CrossMark}

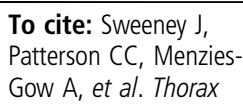

\section{ABSTRACT}

Objective To determine the prevalence of systemic corticosteroid-induced morbidity in severe asthma.

Design Cross-sectional observational study. Setting The primary care Optimum Patient Care Research Database and the British Thoracic Society Difficult Asthma Registry.

Participants Optimum Patient Care Research Database (7195 subjects in three age- and gender-matched groups) - severe asthma (Global Initiative for Asthma (GINA) treatment step 5 with four or more prescriptions/ year of oral corticosteroids, $n=808$ ), mild/moderate asthma (GINA treatment step 2/3, $n=3975$ ) and nonasthma controls $(n=2412) .770$ subjects with severe asthma from the British Thoracic Society Difficult Asthma Registry (442 receiving daily oral corticosteroids to maintain disease control).

Main outcome measures Prevalence rates of morbidities associated with systemic steroid exposure were evaluated and reported separately for each group. Results 748/808 (93\%) subjects with severe asthma had one or more condition linked to systemic corticosteroid exposure (mild/moderate asthma 3109/ 3975 (78\%), non-asthma controls 1548/2412 (64\%); $p<0.001$ for severe asthma versus non-asthma controls). Compared with mild/moderate asthma, morbidity rates for severe asthma were significantly higher for conditions associated with systemic steroid exposure (type II diabetes $10 \%$ vs $7 \%, \mathrm{OR}=1.46$ ( $95 \% \mathrm{Cl} 1.11$ to 1.91$)$, $\mathrm{p}<0.01$; osteoporosis $16 \%$ vs $4 \%, \mathrm{OR}=5.23,(95 \% \mathrm{Cl}$ 3.97 to 6.89 ), $p<0.001$; dyspeptic disorders (including gastric/duodenal ulceration) $65 \%$ vs $34 \%, O R=3.99$, (95\% Cl 3.37 to 4.72), $\mathrm{p}<0.001$; cataracts $9 \%$ vs $5 \%$, $\mathrm{OR}=1.89,(95 \% \mathrm{Cl} 1.39$ to 2.56$), \mathrm{p}<0.001)$. In the British Thoracic Society Difficult Asthma Registry similar prevalence rates were found, although, additionally, high rates of osteopenia $(35 \%)$ and obstructive sleep apnoea $(11 \%)$ were identified.

Conclusions Oral corticosteroid-related adverse events are common in severe asthma. New treatments which reduce exposure to oral corticosteroids may reduce the prevalence of these conditions and this should be considered in cost-effectiveness analyses of these new treatments.

\section{Key messages}

What is the key question?

- What is the prevalence of systemic corticosteroid-induced morbidity in severe asthma?

What is the bottom line?

- This study provides for the first time, prevalence data for common systemic corticosteroid adverse effects in severe asthma, including type II diabetes, osteopenia/ osteoporosis, dyspeptic disorders, obesity, hypertension, cataracts and obstructive sleep apnoea.

\section{Why read on?}

- These prevalence data will be helpful in cost-effectiveness analyses for new biological treatments with corticosteroid-sparing activity in severe asthma and in identifying the need for systematic screening programmes in severe asthma.

\section{INTRODUCTION}

Patients with severe asthma (SA) pose a significant challenge to healthcare professionals. Despite treatment with high-dose inhaled corticosteroids plus a second controller and/or systemic corticosteroid therapy, most still have poor asthma control, persistent airflow limitation and frequent severe exacerbations. ${ }^{1}$ Evidence shows that adverse effects occur in various populations with respiratory disease and other non-respiratory conditions receiving frequent oral corticosteroids (OCS). ${ }^{2-15}$ Many of the studies of respiratory disease included small numbers, were in mixed-disease populations, did not have control groups or relied on commercial healthcare reimbursement claims data or patient self-reporting of symptoms or morbidity, but few prevalence data are available in a well- 
characterised cohort with SA. It is important to define the prevalence of systemic corticosteroid-induced morbidity in this specific population to understand the consequences of progression to maintenance OCS and thus to determine the potential benefit of new steroid-sparing treatments in SA. Prevalence data are also key to informing cost-effectiveness analyses for these new asthma treatments with specific corticosteroidsparing strategies

Common corticosteroid adverse effects range from psychological effects such as irritability, sleep disturbance and increased appetite to severe and potentially life-threatening conditions such as diabetes, cardiovascular disorders and adrenal suppression. $^{2-6}$ These major adverse effects are a substantial healthcare and economic burden and have a major detrimental effect on patients and their families and carers. However, even minor effects, although having a negligible economic burden, may have a significant impact on patients' quality of life, with associated physical and psychosocial impairment. All these effects will affect patients' willingness to adhere to treatment.

The aim of this study was to provide precise prevalence data of adverse events associated with systemic steroid exposure in well-characterised SA.

\section{METHODS}

Data from the Optimum Patient Care Research Database (OPCRD) ${ }^{16}$ and British Thoracic Society (BTS) Difficult Asthma Registry ${ }^{17}$ (both described in the online supplementary data) were used to identify the cross-sectional prevalence of conditions due to systemic corticosteroid exposure in patients with SA. The most commonly reported adverse effects of OCS use are listed in online supplementary table E1 and the data were examined for these outcomes. ${ }^{2-15}$

The OPCRD is a UK respiratory database containing anonymised primary care data supplemented with information from patient-reported questionnaires. The BTS Registry collects data from UK dedicated Specialist Difficult Asthma Services and is hosted online by Dendrite Clinical Systems and admits password-protected anonymised data, after fully informed written consent.

\section{SUBJECTS}

\section{Optimum Patient Care Research Database}

We compared patients with SA requiring regular OCS (defined as Global Initiative for Asthma (GINA) step 5 treatment and four or more prescriptions for OCS in each of two consecutive study years) with patients with mild/moderate asthma and non-asthmatic controls. Subjects had at least 2 years of continuous medical records and were aged $>12$ years. We identified two control cohorts, individually matched to the SA cohort for age, gender and year of birth, one with mild/moderate asthma (asthma diagnosis, GINA step 2/3), the other consisting of non-asthmatic controls (rhinitis diagnosis with no asthma diagnosis/asthma drugs and no exposure to OCS). Full details of cohort definition are available in the online supplementary data. A subgroup of subjects with SA who received maintenance systemic corticosteroids, quantified by six or more OCS prescriptions in both years of the study, was further evaluated (see online supplementary data and table E3 for results).

\section{BTS Registry}

We performed an additional analysis of prevalence rates of conditions associated with systemic steroid exposure in subjects with SA who had detailed follow-up data in the BTS Registry for at least 1 year $(n=770)$. Two groups were defined-group 1 - subjects, who after detailed systematic assessment required daily systemic corticosteroid therapy to maintain asthma control $(n=442$, severe OCS-dependent asthma (CSD)) and group 2, subjects with SA who did not require maintenance OCS but required frequent rescue courses of corticosteroids $(n=328$, severe non-corticosteroid-dependent asthma (NCSD)).

\section{Data analysis}

Statistical analysis was performed using SPSS for Windows V.19. Demographic data are presented as absolute values (\%), mean $\pm \mathrm{SD}$ if normally distributed or median and IQR where not normally distributed. Group differences were examined using the two-sample $t$ test, Mann-Whitney $U$ test or $\chi^{2}$ test, as appropriate.

Disease prevalence estimates are presented as both absolute numbers and percentages with 95\% CIs. Existing morbidities

Table 1 Demographic details of the OPCRD cohorts (for list of steroid-induced morbidities see online supplementary table E1)

\begin{tabular}{|c|c|c|c|c|c|}
\hline Demographics & All $(n=7195)$ & Severe asthma $(n=808)$ & $\begin{array}{l}\text { Mild/moderate } \\
\text { asthma }(n=3975)\end{array}$ & $\begin{array}{l}\text { Non-asthma } \\
\text { controls }(n=2412)\end{array}$ & $p$ Value \\
\hline Female, $n(\%)$ & $4503(63)$ & $507(63)$ & $2515(63)$ & $1481(61)$ & - \\
\hline Age (years) ${ }^{*}$ & $58 \pm 17$ & $59 \pm 17$ & $58 \pm 16$ & $58 \pm 17$ & - \\
\hline \multicolumn{6}{|l|}{ Geographical region, n (\%) } \\
\hline London & $597(8)$ & $55(7)$ & $344(9)$ & $198(8)$ & 0.06 \\
\hline South of England & $903(13)$ & $93(12)$ & $477(12)$ & $333(14)$ & \\
\hline East of England & $1064(15)$ & $115(14)$ & $616(15)$ & $333(14)$ & \\
\hline Midlands & $2146(30)$ & $248(31)$ & $1213(31)$ & $685(28)$ & \\
\hline North of England & $1648(23)$ & $193(24)$ & $874(22)$ & $581(24)$ & \\
\hline Scotland/NI/Wales/unknown & $837(12)$ & $104(13)$ & $451(11)$ & $282(12)$ & \\
\hline \multicolumn{6}{|c|}{ Number of corticosteroid-related comorbiditiest $\mathrm{n}(\%)$} \\
\hline 0 & $1790(25)$ & $60(7)$ & $866(22)$ & $864(36)$ & $<0.001$ \\
\hline 1 & $1754(24)$ & $136(17)$ & $1044(26)$ & $574(24)$ & \\
\hline 2 & $1382(19)$ & $181(22)$ & $797(20)$ & $404(17)$ & \\
\hline$\geq 3$ & $2269(32)$ & $431(53)$ & $1268(32)$ & $570(24)$ & \\
\hline \multicolumn{6}{|c|}{$\begin{array}{l}\text { p Values are not provided for age/gender as cohorts were matched based on age/gender. } \\
\text { *Mean } \pm \text { SD. } \\
\text { tSee online supplementary table E1 for morbidities examined. } \\
\text { OPCRD, Optimum Patient Care Research Database. }\end{array}$} \\
\hline
\end{tabular}


recorded at any time in the data were evaluated and reported separately for each group. In the OPCRD, the proportions of subjects with SA, mild/moderate asthma and non-asthma controls with OCS morbidity were obtained using cross-tabulations. Conditional logistic regression analysis was then used to estimate the OR, 95\% CIs and $\mathrm{p}$ values for the SA cohort relative to each control group taking account of the matched nature of the cohorts. In the BTS Registry, OR and 95\% CIs were obtained from logistic regression analysis, adjusting for potential confounding variables such as hospital, age and gender. A p value of $<0.05$ was considered statistically significant.

\section{RESULTS}

\section{Optimum Patient Care Research Database}

Demographics of all subjects are presented in table 1.

In subjects with SA, there was a predominance of women $(63 \%)$ with a mean age of $59 \quad( \pm 17)$ years. Potential corticosteroid-induced morbidities were identified in $93 \%$ of subjects with SA and 53\% had three or more morbidities, which was significantly higher than for both mild/moderate asthma and non-asthmatic controls (table 1 and online supplementary table E1, $\mathrm{p}<0.001)$.

For subjects where complete and detailed prescribing records where available for the 2 study years $(n=470)$, the median daily dose of prednisolone in SA was $5 \mathrm{mg}$ (IQR 3-9 $\mathrm{mg}$ ) and $0 \mathrm{mg}(0-$ $1 \mathrm{mg}$ ) in mild/moderate asthma, with zero OCS exposure in the non-asthma control cohort. Similarly, the cumulative OCS dose over the 2 study years was median $3920 \mathrm{mg}$ (IQR 2395-6500 mg) in SA and $250 \mathrm{mg}(150-420 \mathrm{mg})$ in mild/moderate asthma.

Table 2 describes the observed prevalence rates of the comorbidities examined across SA, mild/moderate asthma and non-asthma controls. The most prevalent comorbidities identified in subjects with SA were dyspeptic disorders (65\%), obesity $(42 \%)$, psychiatric disorders (38\%), hypertension (34\%), osteoporosis (16\%), hypercholesterolaemia (15\%), chronic kidney disease (14\%), type II diabetes (10\%), osteopenia (10\%) and cardiovascular disease (10\%).

With the exception of glaucoma and hypercholesterolaemia, subjects with SA had a significantly higher risk $(\mathrm{OR}>1)$ of all other adverse effects previously linked to OCS exposure than subjects with mild/moderate asthma. The odds of having type II diabetes, cataracts, sleep disorders, fractures and chronic kidney disease was 1.5-2 times higher for subjects with SA than for those with mild/moderate asthma. The odds of dyspeptic disorder was almost four times higher in SA while the odds of having osteopenia or osteoporosis in SA was over five times higher in SA than in mild/moderate asthma.

Comparison of patients with SA with non-asthma controls showed that all morbidities examined were significantly more prevalent in SA, with the exception of glaucoma. The odds of having type II diabetes, cardiovascular disease, hypertension, psychiatric disorders and fractures was 1.5-2 times higher in SA than in non-asthma controls. The odds of obesity (body mass index $>30 \mathrm{~kg} / \mathrm{m}^{2}$ ) in SA were doubled compared with nonasthma controls. The odds of dyspeptic disorders were almost five times higher while sleep disorders, cataracts and chronic kidney disease were over twice as likely in subjects with SA. The odds of osteoporosis or osteopenia in SA was almost seven times that of the non-asthma controls.

\section{BTS Registry}

Demographic details and clinical data of the BTS Registry cohorts are available in table 3. It is important to emphasise that the comparator NCSD cohort, although not receiving maintenance OCS, had significant rescue systemic corticosteroid exposure despite high-dose inhaled corticosteroids, consistent with SA (median IQR rescue OCS prescriptions $4(2-6)$ in the 12 months before referral). The primary purpose of this analysis was to understand the consequences of progression to daily maintenance OCS compared with frequent rescue steroids.

Again, subjects overall with SA were more likely to be female but there was a greater proportion in the NCSD cohort. Baseline body mass index was significantly lower in the NCSD cohort than in the CSD cohort. The NCSD cohort was more likely to be in full time employment, with significantly fewer not working owing to their asthma. Subjects in the noncorticosteroid cohort were more likely to be current smokers.

Pre-bronchodilator $\mathrm{FEV}_{1}$ was significantly higher and less obstructive in the non-corticosteroid cohort $(77.42 \pm 25.09 \%$ predicted vs $66.70 \pm 24.05 \%$ predicted, $\mathrm{p}<0.001)$. For healthcare use at baseline, subjects in the severe NCSD cohort had significantly fewer unscheduled visits to their general practitioner or to Accident and Emergency $(p=0.035)$ and hospital admissions in the previous 12 months $(\mathrm{p}<0.001)$. Previous admission to the intensive therapy unit (ITU) was also lower $(\mathrm{p}<0.001)$, although overall ITU admission rates were low in both cohorts.

Despite not receiving maintenance OCS, the NCSD cohort were exposed to frequent rescue courses of OCS (median 4 (IQR 1-6)), although pre-referral rescue OCS courses were significantly higher in the CSD cohort (median 5 (IQR 2-8)), as was the inhaled corticosteroid dose (2000 (1600-2000) vs 2000 (1000-2000) $\mu \mathrm{g}$ beclomethasone dipropionate equivalent) and daily short-acting $\beta$-agonist use (median 8 (4-10) vs 6 (4-10).

Hospital Anxiety and Depression Scale (HADS, $n=510$ ), Asthma Quality of Life Questionnaire (AQLQ, $n=434)$ and EuroQoL (EQ-5D, $n=414$ ) data were available to assess anxiety/depression, asthma and generic-related quality of life scores. Mean anxiety scores were $>8$, suggestive of mild anxiety in both cohorts but, additionally, depression scores for subjects with severe corticosteroid-dependent asthma were significantly higher than in those with non-corticosteroid asthma $(\mathrm{p}=0.001)$, although remained in the normal range.

Quality-of-life scores were significantly lower for subjects in the CSD cohort for both EQ-5D domain and Visual Analogue Scale scores. AQLQ scores were also significantly higher for subjects not receiving maintenance OCS across all domains (see table 3).

Potential corticosteroid-induced morbidities were more commonly seen in subjects receiving maintenance OCS than in subjects with NCSD, with $20 \%$ of subjects with NCSD asthma having three or more comorbidities compared with $53 \%$ of subjects with CSD asthma (table 3 and online supplementary table $\mathrm{E} 1, \mathrm{p}<0.001)$.

\section{Prevalence of corticosteroid-induced morbidity in subjects with NCSD in the BTS Registry}

The prevalence rates of the major adverse effects examined (see online supplementary table E1) were significantly lower in the NCSD cohort with the exception of osteoporosis, osteopenia, cardiovascular disease and glaucoma (table 4). However, high rates of obesity (45\%), psychiatric disorders (14\%), dyspeptic symptoms (48\%) and hypertension (15\%) were still apparent in the NCSD cohort. After controlling for age, hospital and gender, associations with severe CSD asthma were strongest for type II diabetes and obstructive sleep apnoea.

Eighty-nine percent of those with NCSD asthma with a report of psychiatric disorder had completed HADS at baseline compared with $69 \%$ of those with corticosteroid-dependent 
Table 2 Prevalence rates of potential systemic corticosteroid-induced comorbidity and comparisons by groups in the OPCRD dataset

\begin{tabular}{|c|c|c|c|c|c|c|c|}
\hline Morbidity & $\begin{array}{l}\text { Severe asthma } \\
(\%)(n=808)\end{array}$ & $\begin{array}{l}\text { Mild/moderate } \\
\text { asthma }(\%)(n=3975)\end{array}$ & OR $(95 \% \mathrm{Cl})^{*}$ & p Value* & $\begin{array}{l}\text { Non-asthma controls } \\
(\%)(n=2412)\end{array}$ & OR $(95 \% \mathrm{Cl})^{*}$ & $p$ Value* \\
\hline Type II diabetes & $82(10)$ & $281(7)$ & 1.46 (1.11 to 1.91$)$ & 0.006 & $149(6)$ & 1.76 (1.30 to 2.38$)$ & $<0.001$ \\
\hline Obesity (BMI >30 kg/m²) & $339(42)$ & $1385(35)$ & 1.36 (1.16 to 1.59$)$ & $<0.001$ & $561(23)$ & 2.04 (1.74 to 2.39$)$ & $<0.001$ \\
\hline Osteopenia & $78(10)$ & $85(2)$ & 5.26 (3.75 to 7.37$)$ & $<0.001$ & $41(2)$ & 6.68 (4.28 to 10.43$)$ & $<0.001$ \\
\hline Osteoporosis & $126(16)$ & $162(4)$ & 5.23 (3.97 to 6.89$)$ & $<0.001$ & $74(3)$ & 6.53 (4.63 to 9.21$)$ & $<0.001$ \\
\hline Fracture & $41(5)$ & $134(3)$ & 1.54 (1.06 to 2.22$)$ & 0.022 & $88(4)$ & 1.65 (1.14 to 2.39$)$ & 0.007 \\
\hline Dyspeptic disorders & $524(65)$ & 1331 (34) & 3.99 (3.37 to 4.72$)$ & $<0.001$ & $578(24)$ & 4.88 (4.11 to 5.79$)$ & $<0.001$ \\
\hline Glaucoma & $32(4)$ & $137(3)$ & 1.12 (0.75 to 1.68$)$ & 0.58 & $67(3)$ & 1.41 (0.89 to 2.25 ) & 0.15 \\
\hline Cataract & $70(9)$ & $195(5)$ & 1.89 (1.39 to 2.56$)$ & $<0.001$ & $105(4)$ & 2.42 (1.70 to 3.43$)$ & $<0.001$ \\
\hline Cardiovascular disease & $77(10)$ & $277(7)$ & 1.36 (1.02 to 1.81$)$ & 0.035 & $168(7)$ & 1.57 (1.14 to 2.15$)$ & 0.005 \\
\hline Hypertension & $276(34)$ & $1145(29)$ & 1.35 (1.12 to 1.61$)$ & 0.001 & $596(25)$ & 1.76 (1.44 to 2.14$)$ & $<0.001$ \\
\hline $\begin{array}{l}\text { Psychiatric conditions/anxiety/ } \\
\text { depression }\end{array}$ & $310(38)$ & $1238(31)$ & 1.43 (1.22 to 1.69$)$ & $<0.001$ & $607(25)$ & 1.67 (1.42 to 1.97$)$ & $<0.001$ \\
\hline Hypercholesterolaemia & $124(15)$ & 561 (14) & 1.15 (0.92 to 1.44$)$ & 0.21 & $258(11)$ & 1.61 (1.25 to 2.08 ) & $<0.001$ \\
\hline Sleep disorder & $33(4)$ & $99(2.5)$ & 1.70 (1.13 to 2.53$)$ & 0.010 & $40(2)$ & 2.21 (1.46 to 3.35$)$ & $<0.001$ \\
\hline Chronic kidney disease & $110(14)$ & $342(9)$ & 1.80 (1.39 to 2.32$)$ & $<0.001$ & $167(7)$ & 2.41 (1.81 to 3.21$)$ & $<0.001$ \\
\hline
\end{tabular}

asthma. Clinically significant anxiety symptoms were confirmed by a HADS-A score $\geq 11$ and were present in the NCSD cohort $(11.54 \pm 5.44)$ while in the corticosteroid-dependent cohort anxiety scores were above normal ranges $(10.69 \pm 4.27)$, although this difference failed to reach statistical significance $(p=0.38)$. HADS depression scores were also higher in those with NCSD asthma and were suggestive of depression in both cohorts and supportive of the diagnosis $(9.29 \pm 5.13$ vs 8.84 $\pm 3.71, \mathrm{p}=0.61$ ), but the difference was not statistically significant.

\section{Prevalence rates for corticosteroid-induced morbidity in OPCRD compared with the BTS Registry}

The selection criteria for SA from OPCRD (GINA step 5 treatment and four or more prescriptions for OCS in each of two consecutive study years) would apply to the majority of subjects in the BTS Registry and we therefore compared morbidity prevalence rates from both datasets (table 5). (Formal statistical comparison of prevalence rates between the OPCRD and the BTS Registry was not thought to be appropriate because of the differing ascertainment methods used in the two sources.)

\section{DISCUSSION}

Treatment with systemic corticosteroids in some patients with SA helps to improve asthma control and reduce exacerbation rates through their anti-inflammatory effects. However, data from the OPCRD and the BTS Difficult Asthma Registry shows that patients with SA have substantial excess morbidity from multiple diseases and adverse effects associated with systemic corticosteroid exposure. Differences are apparent when comparing prevalence rates in subjects with SA who are NCSD but require frequent rescue courses of OCS each year and compared with subjects with mild/moderate asthma and non-asthma controls. To our knowledge, these are the first data reporting prevalence rates of potential systemic corticosteroid-induced comorbidity specifically in subjects with SA.

Most subjects (92-93\%) with SA examined had at least one condition which has been linked to systemic corticosteroid exposure, with significantly higher prevalence rates than in subjects with mild/moderate asthma, and higher again than in subjects examined without asthma. Several studies have investigated comorbidity in patients with asthma compared with non-asthmatic controls but in those studies it is difficult to differentiate asthma severity or systemic corticosteroid exposure and any potential influence on the development of comorbid disease. ${ }^{18-23}$ Steppuhn et al ${ }^{18}$ showed that $60 \%$ of subjects with asthma in their study reported at least one comorbidity, with $18 \%$ reporting at least three comorbidities; similar rates were found in a younger asthmatic population by Karlstad et al. ${ }^{22}$ Our data showed that subjects with mild/moderate asthma (GINA step 2/3 treatment) who are matched for age and gender have a prevalence of comorbidity similar to that of nonasthmatic controls, suggesting that much of the additional comorbidity associated with asthma is due to systemic corticosteroid exposure.

Several systematic reviews in multiple heterogeneous and different patient groups have shown that systemic corticosteroids are a common cause of adverse events in patients exposed to regular doses of OCS. ${ }^{3} 424$ Among the most frequently reported morbidities were osteoporosis, dyspeptic disorders, sleep disturbance, hypertension, diabetes, fractures and cataracts, which is similar to our data in SA. Zazzali et al ${ }^{15}$ demonstrated in a mixed respiratory cohort that the most common adverse effects of OCS use were hypertension, lipid disorders and diabetes. These new data from OPCRD and the BTS Registry have identified strong associations with many of these conditions and others which are associated with the use of OCS in SA.

Data from two different datasets in SA shows that the estimated prevalence for the majority of the corticosteroid-induced morbidities is similar and we believe these estimates are reflective of the prevalence of these conditions in this population. These disease estimates will inform cost analyses in this group to better capture the true effects of regular systemic corticosteroid exposure. Some differences were noted when comparing the OPCRD data with that from the BTS Registry. Higher rates of osteopenia and obstructive sleep apnoea were found in the BTS Registry subjects compared with subjects with SA in the OPCRD and a number of factors may explain these differences. First, subjects from the BTS Registry were receiving substantially higher doses of inhaled corticosteroids than the OPCRD SA 
Table 3 Demographic details, medication, healthcare use and quality-of-life scores British Thoracic Society Severe Asthma Registry at time of initial clinical assessment

\begin{tabular}{|c|c|c|c|c|}
\hline & All $(n=770)$ & $\begin{array}{l}\text { Severe non-corticosteroid- } \\
\text { dependent asthma }(n=328)\end{array}$ & $\begin{array}{l}\text { Severe corticosteroid- } \\
\text { dependent asthma }(n=442)\end{array}$ & $\mathrm{p}$ Value \\
\hline Female (\%) & $502(65)$ & $233(71)$ & $269(61)$ & 0.003 \\
\hline Age in September 2013 & $50 \pm 14.5$ & $48.4 \pm 15.47$ & $50.5 \pm 13.7$ & 0.05 \\
\hline Caucasian (\%) & $694(90)$ & $290(88)$ & $404(91)$ & 0.17 \\
\hline Age (years) asthma diagnosed & $16(4-35)$ & $13(4-35)$ & $18(4-35)$ & 0.38 \\
\hline BMI $\left(\mathrm{kg} / \mathrm{m}^{2}\right)$ & $30.3 \pm 6.9$ & $29.5 \pm 7.1$ & $30.9 \pm 6.7$ & 0.009 \\
\hline \multicolumn{5}{|l|}{ Smoking status } \\
\hline Current (\%) & $61(8)$ & $36(11)$ & $25(6)$ & 0.007 \\
\hline Ex-smoker (\%) & $210(27)$ & $84(26)$ & $126(29)$ & 0.37 \\
\hline \multicolumn{5}{|l|}{ Employment status } \\
\hline Full-time employment (\%) & $307(40)$ & $157(48)$ & $150(34)$ & $<0.001$ \\
\hline Not working due to asthma (\%) & $198(26)$ & $53(16)$ & $145(33)$ & $<0.001$ \\
\hline $\mathrm{FEV}_{1}(\%$ predicted $)$ & $71.27 \pm 25.05$ & $77.42 \pm 25.09$ & $66.70 \pm 24.05$ & $<0.001$ \\
\hline $\mathrm{FEV}_{1} / \mathrm{FVC}$ ratio $(\%)$ & $65.22 \pm 14.96$ & $67.91 \pm 14.49$ & $63.16 \pm 15.01$ & $<0.001$ \\
\hline Median unscheduled visits to GP or A\&E in preceding 12 months (IQR) & $4(2-6)$ & $4(1-6)$ & $4(2-7)$ & 0.035 \\
\hline Median total number of ITU admissions ever (IQR) & $0(0-0)$ & $0(0-0)$ & $0(0-1)$ & $<0.001$ \\
\hline Median hospital admissions in previous 12 months (IQR) & $0(0-2)$ & $0(0-1)$ & $1(0-2)$ & $<0.001$ \\
\hline Median rescue OCS courses in preceding 12 months (IQR) & $4(2-6)$ & $4(1-6)$ & $5(2-8)$ & $<0.001$ \\
\hline Median prednisolone dose (IQR) (mg) & - & - & $15(10-20)$ & - \\
\hline Median BDP equivalent dose & 2000 & 2000 & 2000 & $<0.001$ \\
\hline$(\mathrm{IQR})(\mu \mathrm{g})$ & $(1200-2000)$ & $(1000-2000)$ & $(1600-2000)$ & \\
\hline Median SABA use (IQR) (puffs per day) & $8(4-10)$ & $6(4-10)$ & $8(4-10)$ & 0.002 \\
\hline HADS anxiety & $8.41 \pm 4.82$ & $8.18 \pm 4.95$ & $8.61 \pm 4.72$ & 0.32 \\
\hline HADS depression & $6.55 \pm 4.37$ & $5.83 \pm 4.41$ & $7.15 \pm 4.26$ & 0.001 \\
\hline$E Q-5 D$ & $0.58 \pm 0.34$ & $0.63 \pm 0.33$ & $0.53 \pm 0.33$ & 0.002 \\
\hline EQ-VAS & $55 \pm 21.5$ & $58 \pm 21.9$ & $53 \pm 20.9$ & 0.013 \\
\hline AQLQ symptom score & $3.36 \pm 1.45$ & $3.72 \pm 1.34$ & $3.07 \pm 1.47$ & $p<0.001$ \\
\hline AQLQ activity score & $3.66 \pm 1.30$ & $3.96 \pm 1.35$ & $3.41 \pm 1.22$ & $<0.001$ \\
\hline AQLQ emotional score & $3.32 \pm 1.58$ & $3.74 \pm 1.61$ & $2.98 \pm 1.48$ & $<0.001$ \\
\hline AQLQ environment score & $3.97 \pm 1.57$ & $4.2 \pm 1.52$ & $3.79 \pm 1.58$ & 0.005 \\
\hline AQLQ total score & $3.54 \pm 1.24$ & $3.86 \pm 1.26$ & $3.30 \pm 1.18$ & $<0.001$ \\
\hline \multicolumn{5}{|l|}{ Number of corticosteroid-induced morbidities (\%) (online supplementary table E1) } \\
\hline 0 & $118(15)$ & $82(25)$ & $36(8)$ & $<0.001$ \\
\hline 1 & $182(24)$ & $105(32)$ & $77(17)$ & \\
\hline 2 & $171(22)$ & $75(23)$ & $96(22)$ & \\
\hline$\geq 3$ & $299(39)$ & $66(20)$ & $233(53)$ & \\
\hline
\end{tabular}

Data are shown as mean \pm SD unless otherwise specified.

A\&E, Accident and Emergency; AQLQ, Asthma Quality of Life Questionnaire; BDP, beclomethasone dipropionate; BMI, body mass index; EQ, EuroQoL; GP, general practitioner; HADS, Hospital Anxiety and Depression Scale; ITU, intensive therapy unit; OCS, oral corticosteroids; SABA, short-acting $\beta$ agonist; VAS, Visual Analogue Scale.

cohort. Second, subjects in the BTS Registry all had detailed systematic assessment in specialist centres, where problems such as adherence to treatment and screening for assessment of corticosteroid-induced comorbidities with routine dual energy $\mathrm{X}$ ray absorptiometry scanning and assessment for obstructive sleep apnoea is routine. ${ }^{12526}$ Higher rates of psychiatric disorders, hypertension, cardiovascular disease, glaucoma, cataracts and fractures were evident in subjects with SA in the OPCRD than in the BTS Registry. The advantage of using a primary care database is that recording of such conditions is completed routinely in line with the Quality and Outcomes Framework (QOF) where general practitioners are reimbursed for maintaining disease registers and reviewing patients with certain conditions. Interestingly four out of six of the aforementioned conditions are included in this QOF. It is also possible that these conditions are under-reported in the Registry. It is important that these differences are considered in the future provision of detailed screening programmes for patients with SA exposed to regular systemic corticosteroids.
A new finding of this study is the association with SA and chronic kidney disease, although this is perhaps not surprising considering the high prevalence rates of overlapping major risk factors, including diabetes, hypertension and obesity. This study supports the importance of inclusion of early and regular assessment and prevention measures as part of the systematic management of these patients in order to avoid progression to dialysis and risk of other costly consequences such as cardiovascular disease and premature death.

Using data from the BTS Registry we have been able to demonstrate that regular daily corticosteroid exposure is associated with a measurably greater prevalence of corticosteroid-associated morbidities compared with subjects with severe disease receiving frequent rescue courses. We were also able to demonstrate significantly lower asthma and generic quality-of-life scores in asthma requiring maintenance corticosteroids and taken together, this suggests that the move to daily corticosteroids, while potentially providing better asthma control and reduced exacerbation risk, is likely to have a major 
Table 4 Prevalence rates of corticosteroid-induced morbidity and comparisons between cohorts in the BTS Registry

\begin{tabular}{|c|c|c|c|c|c|c|}
\hline Disease/adverse event & $\begin{array}{l}\text { Severe } \\
\text { corticosteroid- } \\
\text { dependent } \\
\text { asthma (442) } \\
\mathrm{n}(\%)\end{array}$ & $\begin{array}{l}\text { Severe non- } \\
\text { corticosteroid-dependent } \\
\text { asthma (328) } \\
\mathrm{n}(\%)\end{array}$ & OR $(95 \% \mathrm{Cl})^{*}$ & OR $(95 \% \mathrm{CI}) \dagger$ & OR $(95 \% \mathrm{CI}) \ddagger$ & $\mathrm{p}$ Value \\
\hline \multicolumn{7}{|l|}{ Endocrine disorder } \\
\hline IDDM & $2(0.5)$ & $1(0.3)$ & - & - & - & 1.00 \\
\hline NIDDM & 64 (14) & $15(5)$ & 3.55 (1.98 to 6.35$)$ & 3.50 (1.94 to 6.24$)$ & 3.48 (1.94 to 6.26$)$ & $<0.001$ \\
\hline \multicolumn{7}{|l|}{ Cardiac disease } \\
\hline Hypertension & $98(22)$ & 49 (15) & 1.61 (1.11 to 2.36$)$ & 1.59 (1.07 to 2.36$)$ & 1.59 (1.07 to 2.37$)$ & 0.012 \\
\hline Cardiovascular disease & $27(6)$ & $25(8)$ & $0.78(0.44$ to 1.37$)$ & 0.74 (0.41 to 1.33 ) & 0.71 (0.39 to 1.30$)$ & 0.41 \\
\hline Hypercholesterolaemia & $76(17)$ & $24(7)$ & 2.61 (1.60 to 4.23$)$ & 2.64 (1.60 to 4.37$)$ & 2.59 (1.57 to 4.30$)$ & $<0.001$ \\
\hline \multicolumn{7}{|l|}{ Osteoporosis and bone disease } \\
\hline Osteoporosis & $57 / 319(18)$ & $18 / 122(15)$ & $1.26(0.71$ to 2.24$)$ & 1.27 (0.71 to 2.28 ) & 1.21 (0.67 to 2.17 ) & 0.44 \\
\hline Osteopenia & $117 / 319(37)$ & $39 / 122(32)$ & $1.22(0.78$ to 1.90$)$ & 1.23 (0.79 to 1.92 ) & 1.15 (0.73 to 1.81$)$ & 0.36 \\
\hline Fracture & $13(3)$ & $1(0.3)$ & - & - & - & 0.007 \\
\hline Obesity $\left(\mathrm{BMI}>30 \mathrm{~kg} / \mathrm{m}^{2}\right)$ & $237(54)$ & $147(45)$ & 1.43 (1.07 to 1.91$)$ & 1.41 (1.06 to 1.88$)$ & 1.47 (1.10 to 1.97$)$ & 0.016 \\
\hline Weight gain & $55(12)$ & $3(1)$ & - & - & - & $<0.001$ \\
\hline \multicolumn{7}{|l|}{ Sleep disorders } \\
\hline Sleep disturbance & $18(4)$ & $2(1)$ & - & - & - & 0.003 \\
\hline Obstructive sleep apnoea & $51(12)$ & $13(4)$ & 3.14 (1.68 to 5.89$)$ & 3.07 (1.64 to 5.77 ) & 2.80 (1.48 to 5.29$)$ & $<0.001$ \\
\hline \multicolumn{7}{|l|}{ Eye disease } \\
\hline Cataracts & $25(6)$ & $0(0)$ & - & - & - & 0.002 \\
\hline Glaucoma & $8(2)$ & $6(2)$ & 0.97 (0.33 to 2.83$)$ & 0.93 (0.31 to 2.74 ) & 0.83 (0.28 to 2.50$)$ & 0.98 \\
\hline Dyspeptic disorders & $283(64)$ & $157(48)$ & 2.00 (1.49 to 2.68$)$ & 1.94 (1.44 to 2.61$)$ & 1.96 (1.45 to 2.64$)$ & $<0.001$ \\
\hline \multicolumn{7}{|l|}{ Psychiatric disorders } \\
\hline Depression/anxiety/low mood & $125(28)$ & $46(14)$ & 2.36 (1.62 to 3.44$)$ & 2.39 (1.64 to 3.49$)$ & 2.57 (1.76 to 3.76$)$ & $<0.001$ \\
\hline Skin conditions & $16(4)$ & $1(0.3)$ & - & - & - & 0.002 \\
\hline \multicolumn{7}{|l|}{ Corticosteroid-related diseases } \\
\hline Cushingoid symptoms & $27(6)$ & $1(0.3)$ & - & - & - & $<0.001$ \\
\hline Adrenal insufficiency & $12(3)$ & $1(0.3)$ & - & - & - & 0.010 \\
\hline $\begin{array}{l}\text { Corticosteroid-induced proximal } \\
\text { myopathy }\end{array}$ & $1(0.2)$ & 0 & - & - & - & 1.00 \\
\hline
\end{tabular}

impact on patient morbidity and overall well-being. The influence of comorbidity on quality of life and functional status has previously been studied and shown to have a negative impact on quality-of-life scores. ${ }^{19}$ Additionally, subjects in the corticosteroid-dependent group were less likely to be in fulltime employment and more likely to report impairment at work causing a reduction in working hours or complete inability to work. All of these constitute indirect costs of SA with a further link to daily OCS use and are likely to account for a substantial amount of overall costs for this cohort.

The presence of comorbidity places a substantial burden on individuals and healthcare systems, irrespective of the underlying cause. These data have shown that most subjects with SA have multiple conditions which need to be managed and prevented where possible. Previous studies have shown that comorbid conditions and, in particular, asthma-related comorbidity, is associated with increased healthcare use and with a negative effect on health status, functional impairment and quality of life. ${ }^{19-21} 2728$ Taken collectively, these effects have major implications for patients with SA and also for specialists aiming to provide effective management of these patients, as well as placing a substantial burden on healthcare systems. It is worth mentioning that the mean age of subjects from both the BTS Registry and OPCRD is early to mid-50s and with such a heavy burden of comorbidity identified, the long-term implications of costs in this population would be considerable. Even at the age of 50 , patients may be on a path towards a long-term burden of multiple chronic diseases with substantial healthcare and personal costs.

Our analysis has a number of potential limitations. Owing to the cross-sectional nature of the datasets, the causality of effects is difficult to ascertain. These conditions might have preceded OCS use. However, the difference between subjects with SA receiving maintenance OCS and those receiving frequent courses of OCS for long periods does suggest a causal relationship between regular (daily) OCS use and the additional morbidity. Additionally, supporting this argument, the adverse effects we explored are all recognised as being associated with corticosteroid exposure. We were interested in investigating the influence of the dose and duration of treatment on the occurrence of adverse effects in a population exposed to oral corticosteroids. However, owing to the nature of the data from both the BTS Registry and OPCRD, it is difficult to identify the date at which significant systemic steroid exposure started and many of these subjects might have been exposed to systemic steroids for decades from a time when prescription records are not available 
Table 5 Prevalence rates: OPCRD compared with the BTS Registry

\begin{tabular}{|c|c|c|c|c|}
\hline Morbidity & $\begin{array}{l}\text { OPCRD } \\
\text { Severe asthma } \\
n=808(\%)\end{array}$ & $95 \% \mathrm{Cl}$ & $\begin{array}{l}\text { BTS (all subjects) } \\
\mathrm{n}=770(\%)\end{array}$ & $95 \% \mathrm{Cl}$ \\
\hline Type II diabetes & 10 & (8 to 12 ) & 10 & (8 to 13 ) \\
\hline Obesity (BMI >30) & 42 & (39 to 45 ) & 50 & (46 to 53 ) \\
\hline Osteopenia & 10 & (8 to 12 ) & 35 & (31 to 40$)$ \\
\hline Osteoporosis & 16 & (13 to 18$)$ & 17 & (14 to 21$)$ \\
\hline Fracture & 5 & (4 to 7 ) & 2 & (1 to 3 ) \\
\hline Dyspeptic disorders & 65 & (61 to 68$)$ & 57 & (54 to 61 ) \\
\hline Glaucoma & 4 & (3 to 6 ) & 2 & (1 to 3 ) \\
\hline Cataract & 9 & (7 to 11$)$ & 3 & (2 to 5 ) \\
\hline Cardiovascular disease & 10 & (8 to 12 ) & 7 & (5 to 9 ) \\
\hline Hypertension & 34 & (31 to 38 ) & 19 & (16 to 22$)$ \\
\hline Psychiatric disorders & 38 & (35 to 42 ) & 22 & (19 to 25$)$ \\
\hline Hypercholesterolaemia & 15 & (13 to 18$)$ & 13 & (11 to 16$)$ \\
\hline Sleep disorder & 4 & (3 to 6 ) & 11 & (9 to 14$)$ \\
\hline
\end{tabular}

BMI, body mass index; BTS, British Thoracic Society; OPCRD, Optimum Patient Care Research Database.

or accurate. It is also challenging to identify precisely the daily dose of OCS or duration of treatment and whether a subject has taken intermittent frequent steroids or received regular maintenance treatment with less frequent episodic boosts of treatment. We believe that to perform this type of analysis would require a prospective cohort of patients with refractory asthma with data before the onset of OCS exposure. However, given that the definition of severe refractory asthma is predicated on the requirement for high-dose steroid treatment, we believe that identifying such a cohort before initiation of steroids is virtually impossible.

We did not specifically exclude any systemic corticosteroid exposure in the OPCRD cohort with mild/moderate asthma as we wished this group to reflect usual steroid exposure in this group. They had a median OCS dose of $250 \mathrm{mg}$ exposure (which is broadly equivalent to a single rescue course of steroids over a 2-year period). As with all database studies, problems such as coding errors should be considered, and data such as socioeconomic markers were not available. Additionally, there may be a degree of confounding by severity with higher comorbidity detection in patients with SA who frequently attend their general practitioner with asthma. We believe that some of these effects were minimised by 'validating' prevalence rates across the two different datasets, and the similar prevalence rates of type II diabetes, obesity, osteoporosis, dyspeptic disorders and hypercholesterolaemia across the two datasets supports our analysis that these are accurate estimates in this population.

\section{CONCLUSION}

In conclusion, we have identified cross-sectional prevalence rates for adverse effects which are commonly related to systemic corticosteroid use. These rates are greater in subjects with SA who progress to maintenance (daily) corticosteroids than in subjects with SA who have frequent rescue courses and in subjects with mild/moderate asthma.

The most important clinical implication of these findings, given the frequency of these morbidities and the potential effect on patients' health and overall quality of life, is that detailed screening programmes should be in place for patients with SA receiving regular systemic corticosteroids. The need for better targeting of corticosteroid therapy in asthma using objective biomarker-based strategies and the urgent delivery of new treatments which will both reduce exposure to OCS and the overall burden of disease are critical. Ideally, new treatments should be introduced before the introduction of systemic corticosteroids as maintenance treatment to prevent the adverse effects discussed.

\section{Author affiliations}

${ }^{1}$ Centre for Infection and Immunity, Queen's University of Belfast, Belfast, UK ${ }^{2}$ Centre for Public Health, Queen's University of Belfast, Belfast, UK

${ }^{3}$ Royal Brompton Hospital, London, UK

${ }^{4}$ MAHSC, The University of Manchester \& UHSM, Manchester, UK

${ }^{5}$ Severe and Brittle Asthma Unit, Birmingham Heartlands Hospital, Birmingham, UK

${ }^{6}$ Department of Respiratory Medicine, Royal Infirmary, Glasgow, UK

${ }^{7}$ Division of Immunology, Infection and Inflammation, Department of Respiratory

Medicine, University of Glasgow and Gartnavel General, Glasgow, UK

${ }^{8}$ Academic Primary Care, University of Aberdeen, Aberdeen, UK

${ }^{9}$ Department of Infection, Inflammation and Immunity, Institute for Lung Health, University of Leicester, Leicester, UK

Acknowledgements We are grateful to the data input staff and medical and nursing staff at the BTS Registry Difficult Asthma Centres. We thank the Respiratory Effectiveness Group for supporting this project.

Contributors Data were acquired by all authors. The study was conceived and designed by JS, CCP, DP and LGH. JS, CCP and LGH were responsible for analysis and interpretation. JS and LGH drafted the manuscript. All authors approved and edited the final version of the manuscript.

Funding This work was supported by unrestricted research grants from Glaxo Smith Kline and F Hoffmann-La Roche Ltd and was performed in collaboration with the Respiratory Effectiveness Group.

Competing interests AM-G: grants and personal fees from Glaxo SmithKline; grants, personal fees and non-financial support from Novartis; personal fees from Napp; grants and personal fees from Roche; grants, personal fees and non-financial support from Boehringer Ingelheim; personal fees from AstraZeneca; personal fees from Chiesi; personal fees from Amgen; personal fees from Johnson \& Johnson, outside the submitted work. RMN: personal fees from lecture fees and advisory boards, outside the submitted work. AHM: personal fees from Napp; personal fees from AstraZeneca; personal fees from Aerocrine; personal fees from Glaxo

SmithKline; grants, personal fees and other from Novartis; personal fees and other from Boehringer; grants and personal fees from Roche, outside the submitted work. RC: grants from Novartis; grants from Roche, Glaxo SmithKline, AstraZeneca, Janssen, Novartis; personal fees from Novartis advisory board meeting; non-financial support from Novartis, Teva and Boehringer Ingelheim, outside the submitted work. DP: other funding from Aerocrine, Almirall, Amgen, AstraZeneca, Boehringer Ingelheim, Chiesi, Meda, Mundipharma, Napp, Novartis and Teva; other from Almirall, Amgen, AstraZeneca, Boehringer Ingelheim, Chiesi, GlaxoSmithKline, Meda, Mundipharma, Napp, Novartis, Pfizer and Teva; grants from the UK National Health Service, British Lung Foundation, Aerocrine, AstraZeneca, Boehringer Ingelheim, Chiesi, Eli Lilly, GlaxoSmithKline, Meda, Merck, Mundipharma, Novartis, Orion, Pfizer, Respiratory Effectiveness Group, Takeda, Teva and Zentiva; other from Almirall, AstraZeneca, Boehringer Ingelheim, Chiesi, Cipla, GlaxoSmithKline, Kyorin, Meda, Merck, Mundipharma, Novartis, Pfizer, SkyePharma, Takeda and Teva; other 
from Mundipharma and Teva, other from Aerocrine, Boehringer Ingelheim, Mundipharma, Napp, Novartis and Teva; other from Almirall, Chiesi, Teva and Zentiva; other from Aerocrine, AKL Ltd, Almirall, Boehringer Ingelheim, Chiesi, Meda, Mundipharma, Napp, Novartis, Orion, Takeda, Teva, Zentiva, outside the submitted work; In addition, DP has a patent AKL Ltd pending and has shares in AKL Ltd, which produces phytopharmaceutical agents. He owns $80 \%$ of Research in Real Life Ltd and its subsidiary social enterprise Optimum Patient Care. CEB: grants and consultancy fees from GSK, AZ/Medlmmune, Novartis, Chiesi, Roche/ Geneentech and BI. LGH: research grants from Glaxo Smith Kline and from Hoffmann la Roche, during the conduct of the study. He has received grant funding from Medimmune, Novartis UK, Roche/Genentech Inc, Astra Zeneca and Glaxo Smith Kline, and has taken part in advisory boards and given lectures at meetings supported by Glaxo Smith Kline, Respivert, Merck Sharpe and Dohme, Nycomed, Boehringer Ingelheim, Novartis and Astra Zeneca. He has received support funding to attend international respiratory meetings (Astra Zeneca, Chiesi, Novartis, Boehringer Ingelheim and Glaxo Smith Kline) and has taken part in asthma clinical trials (GSK, Schering Pough, Synairgen and Roche/Genentech) for which his institution was remunerated. He is academic lead for the MRC Stratified Medicine UK Consortium in Severe Asthma which involves industrial partnerships with Amgen, Johnson \& Johnson, Genentech/Roche, Astra Zeneca/Medimmune, Aerocrine and Vitalograph.

Ethics approval Ethical approval for the BTS Registry was obtained from the Office for Research Ethics Committees Northern Ireland (ORECNI) (reference number 10/NIR02/37). OPCRD is approved by the Trent Multi-Centre Research Ethics Committee for use within clinical research. The study protocol was approved by the Anonymised Data Ethics Protocols and Transparency Committee (ADEPT).

Provenance and peer review Not commissioned; externally peer reviewed.

\section{REFERENCES}

1 Chung KF, Wenzel SE, Brozek JL, et al. International ERS/ATS guidelines on definition, evaluation and treatment of severe asthma. Eur Respir J 2014;43:343-73.

2 Poetker DM, Reh DD. A comprehensive review of the adverse effects of systemic corticosteroids. Otolaryngol Clin North Am 2010;43:753-68.

3 Manson SC, Brown RE, Cerulli A, et al. The cumulative burden of oral corticosteroid side effects and the economic implications of steroid use. Respir Med 2009;103:975-94.

4 Sarnes E, Crofford L, Watson M, et al. Incidence and US costs of corticosteroid-associated adverse events: a systematic literature review. Clin Ther 2011;33:1413-32.

5 Fardet L, Flahault A, Kettaneh A, et al. Corticosteroid-induced clinical adverse events: frequency, risk factors and patient's opinion. $\mathrm{Br} J$ Dermatol 2007; 157:142-8.

6 Shah M, Chaudhari S, McLaughlin TP, et al. Cumulative burden of oral corticosteroid adverse effects and the economic implications of corticosteroid use in patients with systemic lupus erythematosus. Clin Ther 2013;35:486-97.

7 Ethgen 0 , de Lemos Esteves F, Bruyere 0, et al. What do we know about the safety of corticosteroids in rheumatoid arthritis? Curr Med Res Opin 2013;29:1147-60.

8 Walsh $\mathrm{U}$, Wong CA, Oborne J, et al. Adverse effects of oral corticosteroids in relation to dose in patients with lung disease. Thorax 2001;56:279-84.
9 Smyllie $\mathrm{H}$, Connolly C. Incidence of serious complications of corticosteroid therapy in respiratory disease: a retrospective survey of patients in the Brompton Hospital. Thorax 1968;23:571-81.

10 Rees HA, Williams DA. Long-term steroid therapy in chronic intractable asthma. A study of 317 adult asthmatics on continuous steroid therapy for an average period of 2 1/2 years. BMJ 1962;1:1575-9.

11 Lieberman P, Patterson R, Kunske R. Complications of long-term steroid therapy for asthma. J Allergy Clin Immunol 1972;49:329-36.

12 Pearson RB, Baylis J, Smellie H. Treatment of chronic asthma with prednisolone and the newer steroids. BMJ 1961;1:315.

13 Fitzsimons R, Grammer LC, Halwig JM, et al. Prevalence of adverse effects in corticosteroid dependent asthmatics. N Engl Reg Allergy Proc 1988;9:157-62.

14 Zazzali JL, Broder M, Chang E. Oral corticosteroid use increases the risk of glucocorticoid-related adverse events in asthmatics. J Allergy Clin Immunol 2012;129:AB74.

15 Zazzali JL, Broder MS, Omachi MD, et al. Risk of corticosteroid-related adverse events in asthma patients with high oral corticosteroid use. Allergy Asthma Proc 2015;36:268-74.

16 Price D, Ryan D, Burden A, et al. Using fractional exhaled nitric oxide (FeNO) to diagnose steroid-responsive disease and guide asthma management in routine care. Clin Transl Allergy 2013;3:37.

17 Heaney LG, Brightling CE, Menzies-Gow A, et al., British Thoracic Society Difficult Asthma Network. Refractory asthma in the UK: cross-sectional findings from a UK multicentre registry. Thorax 2010;65:787-94.

18 Steppuhn H, Langen U, Scheidt-Nave C, et al. Major comorbid conditions in asthma and association with asthma-related hospitalizations and emergency department admissions in adults: results from the German national health telephone interview survey (GEDA) 2010. BMC Pulm Med 2013;13:46.

19 Adams RJ, Wilson DH, Taylor AW, et al. Coexistent chronic conditions and asthma quality of life: a population-based study. Chest 2006;129:285-91.

20 Zhang T, Carleton BC, Prosser RJ, et al. The added burden of comorbidity in patients with asthma. J Asthma 2009;46:1021-6.

21 Gershon AS, Wang C, Guan J, et al. Burden of comorbidity in individuals with asthma. Thorax 2010;65:612-8.

22 Karlstad $\varnothing$, Nafstad P, Tverdal A, et al. Comorbidities in an asthma population 8-29 years old: a study from the Norwegian Prescription Database. Pharmacoepidemiol Drug Saf 2012;21:1045-52.

23 Park J, Kim T, Joo H, et al. Diseases concomitant with asthma in middle-aged and elderly subjects in Korea: a population-based study. Allergy Asthma Immunol Res 2013;5:16-25.

24 Fardet L, Kassar A, Cabane J, et al. Corticosteroid-induced adverse events in adults. Drug Saf 2007;30:861-81.

25 British Thoracic Society/Scottish Intercollegiate Guidelines Network. British Guideline on the Management of Asthma-A National Clinical Guideline. Revised January 2012. 2012. http://www.brit-thoracic.org.uk/Portals/O/Guidelines/AsthmaGuidelines/ sign 101\%20Jan\%202012.pdf

26 Global Initiative for Asthma (GINA). Global Strategy for Asthma Management and Prevention. 2014. http://www.ginasthma.org/

27 Steppuhn $\mathrm{H}$, Langen U, Keil T, et al. Chronic disease co-morbidity of asthma and unscheduled asthma care among adults: results of the national telephone health interview survey German Health Update (GEDA) 2009 and 2010. Prim Care Respir J 2014;23:22-9.

28 Adams RJ, Wilson DH, Taylor AW, et al. Psychological factors and asthma quality of life: a population based study. Thorax 2004;59:930-5. 